\title{
Shea Butter (Vitellaria paradoxa) Biodiesel
}

\section{ABSTRACTS}

${ }^{*}$ E.I. Bello and ${ }^{\dagger} \mathrm{A}$. Mamman

${ }^{*}$ Department of Mechanical Engineering

The Federal University of Technology, Akure.

Email:emmanuelbello111@yahoo.co.uk

${ }^{\dagger}$ Nigeria National Petroleum Company, Lagos, Nigeria.

email:aminumamman@gmail.com

Shea butter was pretreated with sulphuric acid to convert the free fatty acids to esters and then transesterified to biodiesel using methanol and sodium hydroxide as catalyst. The oil, biodiesel, $10 \%$ and $20 \%$ blends with diesel were characterized according to ASTM and EN protocols for biodiesel. The fatty acid profile of the oil and biodiesel were analyzed using HP 6890 Gas Chromatography analyzer fitted with a flame ionization detector. From the results obtained, the properties of the biodiesel are by and large within the ASTM limits for biodiesel and the saturation to unsaturation ratio is 0.87 which gives a good balance of properties. The mineral contents are also within the ASTM limits for biodiesel. From the results obtained, it was concluded that the biodiesel can be used as alternative fuel for diesel engines.

Keywords: Shea butter; oil, biodiesel; characterization; fatty acid profile; mineral elements.

Academic descipline: Mechanical engineering

Subject classification: Fuels and combustions

Type of paper: Original research

\section{Council for Innovative Research}

\author{
Peer Review Research Publishing System
}

\section{Journal: JOURNAL OF ADVANCES IN BIOTECHNOLOGY}

Vol .4, No. 3

www.cirjbt.com , jbteditor@gmail.com 


\section{$1.0 \quad$ INTRODUCTION}

Concerns for the environment resulting from climatic cataclysms such as typhoons, super storms, flooding, draughts, global warming and pollution have led to search for alternative fuels for diesel engines. Vegetable oil has proved a possible alternative but its high viscosity and poor cold flow properties makes direct use problematic without costly transesterification to biodiesel. Biodiesel is obtained by reaction vegetable oil with reagent such as methanol or ethanol in the presence of an alkaline or acid catalyst. It has simple molecular structures that is made up of 6 to 9 fatty acids. Its properties are similar to those of diesel fuel, it is highly biodegradable, has high flash point that makes it safer than diesel and its harmful exhaust emissions is less than that of diesel thus making it more environment friendly. The use of vegetable oil, especially the edible ones can cause food scarcity and high prices hence inedible vegetable oils such as jatropha and castor oil have been investigated. Other oil yielding seeds that grows in the wild have been investigated and one of such oils is the African shea butter that is extracted from the nuts of Karite tree, which can grow up to a height of 20 metres and a massive 1 to 2 metres trunk diameter. It commonly grows in the wild throughout the west African coast and commercial plantation is uncommon because of the long gestation period as it does nut fruit until after 10-20 years and will not achieve maximum yield until about 30 years but it can continue to yield fruit for 200 years. The nut is edible and contains 1, 2 or sometimes 3 seeds which are covered by a thin layer of hull.

The shea butter, is extracted from the seeds by crushing, roasting and grinding the nuts and separating the butter from the resulting paste through a process of kneading and mixing with water to float the butter oil to the surface. It has high content of stearic and oleic fatty acids and contains vitamins A, E and F. It has high saponification value and contains high amount of unsaponifiable matters that have therapeutic values and used for the treatment of skin diseases, wrinkles, arthritis and rheumatism.

Literature search revealed few published works and the few ones available includes Enweremadu and Alamu (2010) who reported the work done on the production and characterization of shea butter biodiesel. The results they obtained are similar to the ones being reported in this paper. Enweremadu et al., (2011) also investigated the relationship between some basic flow properties of shea butter biodiesel and their blends with diesel fuel and developed blending equations for predicting the density, kinematic viscosity, cloud and pour points of biodiesels. Enweremadu et al., (2011) also reported the performance evaluation of a diesel engine fueled with methyl ester of shea butter and concluded that the performance was similar to when diesel was used.

Contaminants in vegetable oils are either absorbed from the pesticides, fungicides, herbicides, trace metals and other minerals used on the soil or get in during processing and these includes Polycyclic hydrocarbons, Polychlorinated cyclic hydrocarbons, trace metals, aflatoxins a toxic fungal metabolite contaminate produced by certain strain of aspergillium flavours and related species in cereals, nuts and oilseeds, Perchloroethylene (PCE from dry cleaning operations), detergents and cleansers, washing water, polar absorption materials and minerals. Their prevalence in fuel are regulated because some have low melting point and can be deposited on engine internal components where they can sinter and form slag that can cause blockage of injector holes and can have adversely affects heat flow (Demirbas, 2004; Werther et al., 2000; Jenkins et al., 1996). Vegetable oils commonly contains calcium, magnesium, sodium, potassium, sulphur and phosphorus (Allica et al., 2001) and these are regulated because of the adverse effect they can have on the engine. Shea butter, despite it several applications has not been well researched, hence the aim of this paper is to provide more information on the physicochemical properties of the oil.

\subsection{MATERIALS AND METHODS}

\subsection{Materials}

The raw shea butter oil was procured from kaiama, in kwara state of Nigeria. Since it was solid at room temperature, it was melted and filtered to remove solid particles and then stored at $4{ }^{\circ} \mathrm{C}$ in the refrigerator before use. Analytical reagents used includes methanol (purity $>99.8 \%$ ), sodium hydroxide (purity $>99 \%$ ), n-hexane (purity $>99$ ) anhydrous sodium sulfate (purity >99), etc. The analytical equipment used and the protocols followed are shown in Table 1.

\subsection{Transesterification}

The oil contained $22 \%$ free fatty acid, which would inhibit biodiesel yield hence it was pretreated with sulphuric acid to convert some to esters and reduce the amount to less than $3 \%$. The alkaline transesterification was done using anhydrous methanol at a molar ratio of 6 to 1 and $0.9 \% \mathrm{w} / \mathrm{w}$ of sodium hydroxide as catalyst. The processor was stirred at $600 \mathrm{rpm}$ at a temperature of $60{ }^{\circ} \mathrm{C}$ for 4 hours after which the mixture was poured into a decanter and allowed to settle overnight so that the reaction can be driven to completion and for the mixture to separate into methyl ester and glycerol. The heavier glycerol at the bottom was drained off by gravity. The excess methanol in the methyl ester was removed in a flash evaporator and other impurities were removed by washing with distilled water of volume ratio 3 to 1 three times. Finally, it was passed through anhydrous sodium sulfate to remove water moisture.

\subsection{Fatty Acid Profile}

The fatty acid profile of the shea butter oil, B100, B10 and B20 and the standard sample of free fatty acids were determined using the HP 6890 Gas Chromatography analyzer that incorporated HP ChemStation Rev A 09.11 [1206] software for data collection and analysis. A Flame lonization Detector (FID) was used and the carrier gas nitrogen. The initial oven temperature was set at $60^{\circ} \mathrm{C}$ and the procedure was as reported by (Bello and Otu, 2011). 


\subsection{Characterization}

The shea butter oil, its methyl ester (B100), 10\% (B10) and 20\% (B20) blends with diesel were characterized according to ASTM and EN protocols as listed in Table 1. Measurements were made in triplicate and the mean reported. Blending was done at $10^{\circ} \mathrm{C}$ above cloud point to prevent the fuel from gelling or segregating.

Table 1. Biodiesel properties test methods

\begin{tabular}{|c|c|c|c|c|c|}
\hline Property & Unit & $\begin{array}{l}\text { Apparatus/ } \\
\text { Equipment }\end{array}$ & Protocol & $\begin{array}{l}\text { ASTM } \\
\text { Limits D6751 }\end{array}$ & $\begin{array}{l}\text { EN Limits } \\
14214\end{array}$ \\
\hline $\begin{array}{l}\text { Specific gravity at } \\
15^{\circ} \mathrm{C}\end{array}$ & $\mathrm{kg} / \mathrm{m}^{2}$ & Glass hydrometer & ASTM D1298 & $860-900$ & $860-900$ \\
\hline Pour point & ${ }^{\circ} \mathrm{C}$ & $\begin{array}{l}\text { Koehler Automated Cloud and } \\
\text { Pour Point System D2709 }\end{array}$ & ASTM 2500 & - & - \\
\hline Cloud point & ${ }^{\circ} \mathrm{C}$ & $\begin{array}{l}\text { Koehler Automated Cloud and } \\
\text { Pour Point System D2709 }\end{array}$ & ASTM2500 & - & - \\
\hline Flash point & ${ }^{\circ} \mathrm{C}$ & $\begin{array}{l}\text { Koehler Pensky-Martens Flash } \\
\text { Cup Tester }\end{array}$ & ASTM D93 & $130 \mathrm{~min}$ & $120 \mathrm{~min}$ \\
\hline Kinematic viscosity & $\mathrm{mm}^{2} / \mathrm{s}$ at $40^{\circ} \mathrm{C}$ & Capillary viscometer & ASTM D445 & $1.9-6.0$ & $3.5-5.0$ \\
\hline $\begin{array}{l}\text { Lower heating } \\
\text { value }\end{array}$ & $\mathrm{kJ} / \mathrm{kg}$ & $\begin{array}{l}\text { Isoperibol oxygen bomb } \\
\text { calorimeter }\end{array}$ & ASTM D240 & - & - \\
\hline Cetane index & - & - & ASTM D613 & $47 \min$ & - \\
\hline lodine value & $\mathrm{mgl}_{2} / \mathrm{g}$ & Titration & EN14111 & 120 & - \\
\hline Peroxide value & $\mathrm{meq} / \mathrm{kg}$ & Titration & EN14111 & - & - \\
\hline Oxidation index & Hours & Oxygen glass ware apparatus & ASTM D2274 & $3 \mathrm{~min}$ & $6 \mathrm{~min}$ \\
\hline $\begin{array}{l}\text { Saponification } \\
\text { value }\end{array}$ & $\mathrm{mg} \mathrm{KOH} / \mathrm{g}$ of oil & Titration & EN14111 & & $120 \max$ \\
\hline $\begin{array}{l}\text { Unsaponifiable } \\
\text { matter }\end{array}$ & $\%$ & Titration & - & & - \\
\hline Free fatty acid & $\%$ oleic acid & Titration & ASTM D6584 & 0.24 & - \\
\hline Acid value & $\mathrm{mgKOH} / \mathrm{g}$ & $\begin{array}{l}\text { KEM AT-150 Automatic } \\
\text { Potentiometric Titrator }\end{array}$ & ASTM D664 & $0.05 \max$ & - \\
\hline Soap content & Ppm & Titration & EN14111 & - & - \\
\hline Water and residue & $\%$ & Centrifuge & ASTM D2709 & $0.05 \max$ & - \\
\hline Moisture content & $\%$ & Karl-Fisher coulometer & ASTM D2709 & - & 360 max \\
\hline Sulphur & $\%$ & Horiba Analyzer Model SLFA-20 & ASTMD5453 & $0.05 \%$ & - \\
\hline Phosphorus & $\%$ & Schoniger flask & - & - & - \\
\hline Mineral analysis & $\mathrm{mg} / \mathrm{kg}$ & $\begin{array}{l}\text { Atomic absorption } \\
\text { spectrophotometer }\end{array}$ & - & - & - \\
\hline $\begin{array}{l}\text { Copper strip } \\
\text { Corrosion }\end{array}$ & scale of 5 & $\begin{array}{l}\text { Koehler K25330 Copper Strip } \\
\text { Test Bath }\end{array}$ & ASTMD130 & No.3 max & - \\
\hline Fatty acid profile & wt (\%) & $\begin{array}{l}\text { HP6890 Chromatography } \\
\text { analyzer }\end{array}$ & & & \\
\hline Free glycerol & $\%$ & 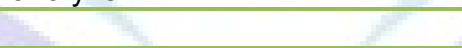 & 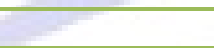 & & \\
\hline Methanol & $\operatorname{lin}_{\operatorname{lin}}$ & 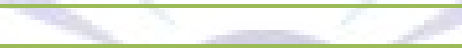 & & & 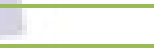 \\
\hline Colour & - & Lovibond colour comparator & & & \\
\hline Refractive index & - & Refractometer & & & \\
\hline $\begin{array}{l}\text { Distillation } \\
\text { Characteristics }\end{array}$ & $\%$ recovery & $\begin{array}{l}\text { Reduced pressure distillation } \\
\text { curve apparatus }\end{array}$ & & & \\
\hline
\end{tabular}

The experiments were carried out in the fuel laboratory of the Federal University of Technology, Akure and in Multienvironment Consultants Laboratory in Lagos, Nigeria.

\subsection{RESULTS AND DISCUSSION}

The results obtained are shown in tables 2- 4 and the discussion that followed refers to them. Shea butter oil is solid at room temperature, the biodiesel contains $41.373 \%$ stearic acid and is $46.754 \%$ saturated as shown in table 3 . From the results in table 2, the properties of the blend are very similar to those of diesel. The biodiesel specific gravity of 0.888 is higher than 0.85 of diesel thus making it a heavier fuel than diesel. 
Table 2. Properties of shea butter biodiesel

\begin{tabular}{|c|c|c|c|c|}
\hline Property & Oil & B100 & B20 & B10 \\
\hline State at room temperature $\left(25^{\circ} \mathrm{C}\right)$ & Solid & Liquid & Liquid & Liquid \\
\hline \multirow[t]{2}{*}{ Colour } & Yellowish & Light & Light & Dark \\
\hline & & Brown & Brown & Brown \\
\hline Specific gravity & - & 0.888 & - & - \\
\hline Pour point $\left({ }^{\circ} \mathrm{C}\right)$ & - & 6 & -12 & -14 \\
\hline Cloud point $\left({ }^{\circ} \mathrm{C}\right)$ & - & 3 & -9 & -11 \\
\hline Flash point $\left({ }^{\circ} \mathrm{C}\right)$ & - & 170 & 132 & 97 \\
\hline Fire Point $\left({ }^{\circ} \mathrm{C}\right)$ & - & 196 & - & - \\
\hline Kinematic viscosity $\left(\mathrm{mm}^{2} / \mathrm{s}\right.$ at $\left.40^{\circ} \mathrm{C}\right)$ & 38.10 & 4.44 & 3.07 & 2.78 \\
\hline Higher heating value (kJ/kg) & 36.73 & 37.98 & 43.44 & 44.96 \\
\hline Lower heating value (kJ/kg) & 38.20 & 38.90 & 43.40 & 42.60 \\
\hline Cetane number & 57.60 & 56.40 & 54.20 & 52.40 \\
\hline lodine value $(\mathrm{g} / 100 \mathrm{~g})$ & 63.9 & 40.40 & - & - \\
\hline Peroxide value (meq/kg) & 12.45 & 0.84 & - & - \\
\hline Oxidation index (Hrs) & 14 & 8 & 20 & 24 \\
\hline Saponification value (mg KOH/g of oil) & 231.92 & 172.4 & - & - \\
\hline Soap content (ppm) & 0.001 & 5.06 & 1.12 & 0.26 \\
\hline Free fatty acid (\%) & 22 & 0.25 & - & - \\
\hline Acid value (mgKOH/g) & 47.2 & 0.27 & - & - \\
\hline Water and residue (\%) & 1.5 & 0.015 & 0.008 & 0.006 \\
\hline Moisture contents (\%) & 0.025 & 0.014 & 0.008 & 0.006 \\
\hline Unsaponifiable matter (\%) & 10 & 0.35 & - & - \\
\hline Refractive Index at $40^{\circ} \mathrm{C}$ & 1.49 & 1.471 & 1.477 & 1.48 \\
\hline Copper strip Corrosion (at $3 \mathrm{hr}, 50^{\circ} \mathrm{C}$ ) & 5 & 3 & 1 & 1 \\
\hline Distillation ( $5 \%$ recovery) ${ }^{\circ} \mathrm{C}$ & 330 & 327 & 240 & 239 \\
\hline Distillation ( $10 \%$ recovery) ${ }^{\circ} \mathrm{C}$ & 333 & 350 & 246 & 243 \\
\hline Distillation (50\% recovery) ${ }^{\circ} \mathrm{C}$ & 356 & 353 & 285 & 282 \\
\hline Distillation (90\% recovery) ${ }^{\circ} \mathrm{C}$ & 365 & 360 & 330 & 332 \\
\hline Free glycerol (\%) & 0.246 & 0.033 & 0.005 & 0.003 \\
\hline Methanol (\%) & 0.001 & 0.061 & 0.022 & 0.011 \\
\hline
\end{tabular}

Table 3. Mineral contents of shea butter oil and biodiesel $(\mathrm{mg} / \mathrm{kg})$

\begin{tabular}{|llllllll|}
\hline S/N & Sample & Sodium & Potassium & Calcium & Magnesium & Sulphur & Phosphorus \\
\hline $\mathbf{1}$ & Oil & 0.02224 & 0.1153 & 0.3178 & 0.6319 & 1.8316 & 32.0825 \\
\hline $\mathbf{2}$ & B100 & 0.0009 & 0.0006 & 0.2131 & 0.3812 & 0.0529 & 3.1962 \\
\hline $\mathbf{3}$ & B10 & 0.0012 & 0.0015 & 0.0024 & 0.0018 & 0.0036 & 0.0062 \\
\hline
\end{tabular}


Table 4. Fatty acid wt\% profile of shea butter oil and Biodiesel.

\begin{tabular}{|l|lll|}
\hline Fatty Acid (wt \%) & Form & Oil & B100 \\
\hline Palmitic & C16:0 & 5.381 & 6.036 \\
\hline Palmitoleic & C16:1 & 0.027 & 0.047 \\
\hline Stearic & C18.0 & 41.373 & 40.433 \\
\hline Oleic & C18:1 & 43.600 & 43.040 \\
\hline Linoleic & C18:2 & 9.407 & 10.070 \\
\hline Linolenic & C18:3 & 0.029 & 0.052 \\
\hline Arachidonic & $\mathrm{C} 20: 4$ & 0.183 & 0.323 \\
\hline Saturation & - & 46.754 & 46.076 \\
\hline Unsaturation & - & 53.246 & 53.532 \\
\hline
\end{tabular}

\subsection{Specific Gravity}

Since the biodiesel was extracted from the oil, the specific gravity is lower than that of the oil. The specific gravity of the oil was 0.91 and reduced to 0.85 for the biodiese6.754l. The specific gravity of biodiesel is within the range 0.86 and 0.90 while diesel is $0.81-0.85$.

\subsection{Cold flow properties}

The cloud and pour points of the biodiesel are just above freezing point of water which limit their use in cold regions the characteristic however improves with blending with diesel.

\subsection{Kinematic viscosity}

The kinematic viscosity of the oil was a high $38.1 \mathrm{~mm}^{2} / \mathrm{s}$ because of the high degree of saturation (46.075\%) since saturated fatty acids are solid at room temperature. It however, reduced with tranesterification to within ASTM limits. Viscosity is important as it affects the atomization of the fuel in the combustion chamber, the momentum of the injected fuel, the capacity to penetrate the highly compressed air in the cylinder and the power required to pump the fuel.

\subsection{Heating value}

Heating value is the enthalpy released after the complete combustion reaction of fuel at a constant pressure or volume. The higher the heating value of the fuel, the lower the fuel consumption required to obtain the same engine power output. The heating values of biodiesel are generally lower than diesel by about 12.7-14.7\% (Monyem and Van Gerpen, 2009). The lower heating values of the oil, biodiesel, B20 and B10 are $38.20 \mathrm{MJ} / \mathrm{kg}, 38.90 \mathrm{MJ} / \mathrm{kg}, 43.40 \mathrm{MJ} / \mathrm{kg}$ and $42.60 \mathrm{MJ} / \mathrm{kg}$ respectively, as shown in Table 2. There are very small differences between the values for higher and lower heating values for the samples.

3.5 Cetane number. The cetane number of B100 was 57.6. This is unusually high for a vegetable oil and well above the minimum limit of 47 for biodiesel in table 1 which can be attributed to the high degree of saturation since saturated fatty acids commonly have high cetane number although solid at room temperature (Gabroski, 2000). Cetane number reduces with increasing blending ratio with diesel.

\subsection{Free fatty acid}

The free fatty acid of the oil was $22 \%$ while that of the biodiesel was $0.25 \%$. Free fatty acid tends to lower catalytic activities, which would reduce the biodiesel yield. Ma et al., (1998) recommended that it should be less than $0.5 \%$. When higher that $3 \%$, the oil should be esterified with an acid to convert some of the free fatty acids to esters before alkaline transesterification.

\subsection{Acid value}

Acid value of the B100 was $0.27 \%$. Oleic acid value determines the balance between cold flow properties and oxidation stability and tendency for soap formation during transesterification. The acid number of a biodiesel can be used to indicate the content of free fatty acids of the fuel. Cvengros and Cvengrosova, [2009] have established that the acid number of a biodiesel increases $3 \mathrm{mg} \mathrm{KOH} / \mathrm{g}$ per $1 \mathrm{wt}$ \% water content in its raw oil. 


\section{8 lodine value}

The iodine value reduced to 40.40 after transesterification which is on the low side and makes it a suitable fuel for diesel engines as far as carbon deposits in the cylinder is concern. lodine value is a measure of the degree of unsaturation of the fuel sample.

\subsection{Peroxide value.}

The peroxide value of the B100 was $0.84 \mathrm{meq} / \mathrm{kg}$. Peroxide value is generally used to determine autoignition and the extent of fuel oxidation and varies with degree of saturation. Self oxidation is common with fuel having highly unsaturated fatty acids. High value is a sign of high degree of rancidity.

\subsection{Oxidation index}

Oxidation is the reaction of biodiesel when in contact with oxygen or catalyst. It is related to the number of double bonds in the fuel. The Oxidation index of the oil of 14 hours reduced to 8 hours after transesterification but increased to 20 and 24 hours for B10 and B20 respectively. Oxidative degradation can result in higher acid value, increased viscosity, formation of gums and sediments and brown colouration of the biodiesel.

\subsection{Saponification value}

This is the moisturizing fraction of the oil and consists of neutral fats and fatty acids. Its uses include treatment of dry and asky skins. It is also used as bleaching agent for the skin. The saponification value of the oil and B100 are 231.72 and $172.5 \mathrm{mg} \mathrm{KOH} / \mathrm{g}$ respectively and is about the average value for biodiesels.

\subsection{The unsaponifiable matter.}

This is the healing fraction and is the matter remaining when the oil has been saponified. The value for oil and B100 are $10 \%$ and $0.35 \%$ respectively. Unsaponifiable matter in the oil consists of phytonutrients, a variety of nonglyceridic bioactive substances containing variable mixture of hydrocarbons, aldehydes, ketones, alcohols, sterols, pigments, and fat-soluble vitamins ( $E$ and $A$ ) that may occur naturally or may be formed during processing or degradation of oils (Badifu, 1991). Some of these matters are removed during water washing hence the lower value for biodiesel. It is used for healing a variety of ailments such as cellular regeneration during wound healing and anti-inflammatory.

\subsection{Soap content}

The Soap content in the oil was $0.001 \mathrm{ppm}$ and increased to $5.06 \mathrm{ppm}$ for the biodiesel which can be attributed to the residue soap that escaped the washing process but it reduced with blending. Engine testing of biodiesel suggests that soap content, although increases cleanliness and lubrication. However, when biodiesel is not adequately washed, the burning quality will be affected thus lowering the power output and thermal efficiency. The effect is also manifested in the form of detonation, irregular combustion, increased vibration of engine structures and thick smoke in the exhaust systems.

\subsection{Water and residue.}

The oil contained $1.5 \%$ water and residue, which reduced to $0.015 \%$ for the B100 after transesterification. For the B10 and $\mathrm{B} 20$, it reduced to $0.008 \%$ and $0.006 \%$ respectively after blending. Water and residue can have adverse effect on the performance of the fuel system as water can freeze during cold weather and block fuel flow. Residues can also accumulate and block fuel filters and injector nozzle holes. Biodiesel in highly solvent and would loosen sediments and increase viscosity. Water can hydrolyze to long chain free fatty acid that would subsequently increase acid value

\subsection{Water moisture}

The water moisture content was $0.025 \%$ for the oil, $0.014 \%$ for the $\mathrm{B} 100,0.008 \%$ and $0.006 \%$ for the $\mathrm{B} 10$ and $\mathrm{B} 20$ respectively. Water moisture in the oil can reduce biodiesel yield during transesterification and can cause corrosion of metallic parts. Hence, greater water content in raw oil will cause a larger acid number for a resulting biodiesel

\subsection{Free Glycerol}

Free Glycerol is the amount of glycerol remaining in the biodiesel after water washing. Although largely removed during water washing because it is insoluble in biodiesel a small amount would remain suspended in the biodiesel. When the amount is high, it will settle at the bottom of the tank in viscous form which can block filters and course irregular combustion in the engine. Free glycerol in the oil was $0.246 \%$, it reduced to $0.033 \%$ for the biodiesel and reduced further with blending.

\subsection{Methanol}

This is the methanol remaining in the biodiesel after water washing transesterification.. Excessive methanol can reduce lubricity, reduce flash point due to its high volatility, distort the operation of the injectors and can affect some materials in the fuel system. The methanol in the biodiesel was $0.061 \%$ and reduce with increasing blending ratio. 


\subsection{Copper strip corrosion}

The shea butter is very corrosive with a maximum score of 5 on a scale of 5 but the biodiesel has a score of 3 which reduced to 1 for the blends, the same corrosively level as diesel. This study is important as some fuel system components are made from copper and its alloys which makes them susceptible to corrosion on exposure to biodiesel.

\subsection{Distillation characteristics}

Fig. 1 shows the distillation characteristics of shea butter oil, biodiesel and blends. The distillation characteristic of the oil and B100 are very close and so is that for B10 and B20. The recovery temperatures for the oil and B100 are much higher than the temperatures for the blends due to the diluting effects of diesel fuel that contained more volatile components. The rate of distillation of the Oil and B100 are fairly uniform and within a temperature range of $30^{\circ} \mathrm{C}$ while that of the blends rose sharply and with a wider temperature range of $90^{\circ} \mathrm{C}$. The distillation temperature is one of the main indicators of the volatility and distribution of light to heavy fatty acids in a biodiesel. When the distillation temperature of $T_{50}$ is low, it implies a lower mass fatty acids which causes a longer ignition delay and a greater degree of knocking while a higher distillation temperature of $T_{90}$ indicates a heavy mass fatty acids, which may cause a slower vaporization rate and inferior atomization of liquid fuel (Cherng-Yuan and Rong-Ji,2009).

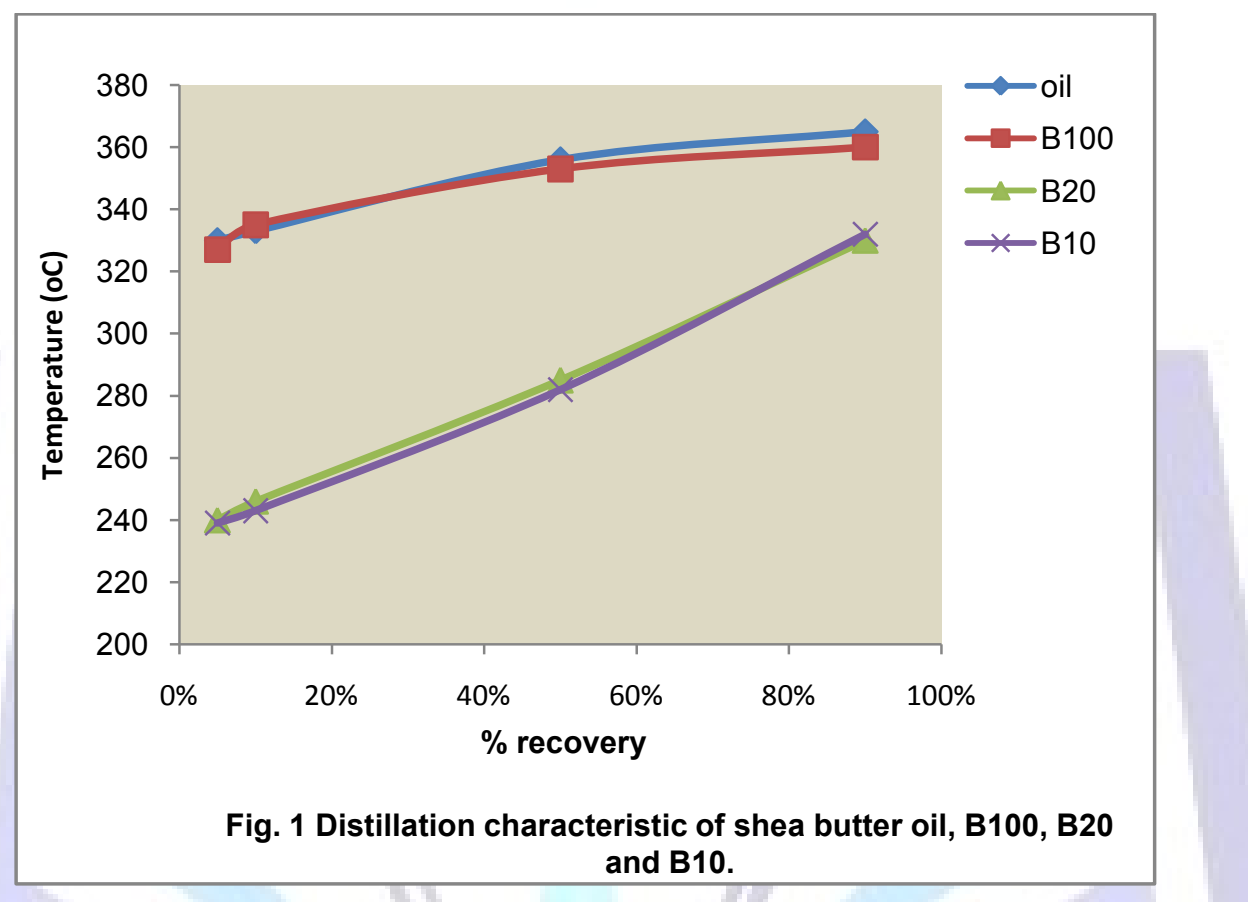

\subsection{Fatty Acid profile}

The oil and biodiesel have 0.86 ratio of saturated versus unsaturated as shown in Fig.2, making it a balanced fuel with a wide range of possible applications. The fatty acid wt \% changed very slightly after transesterification. The oleic acid of $43.6 \%$ for the oil is just below the average value of $45 \%$ for vegetable oils reported by Bello and Agge, 2011 . Oleic acid value gives the balance between favorable cold flow properties, high oxidation stability and tendency for saponification during transesterification. 


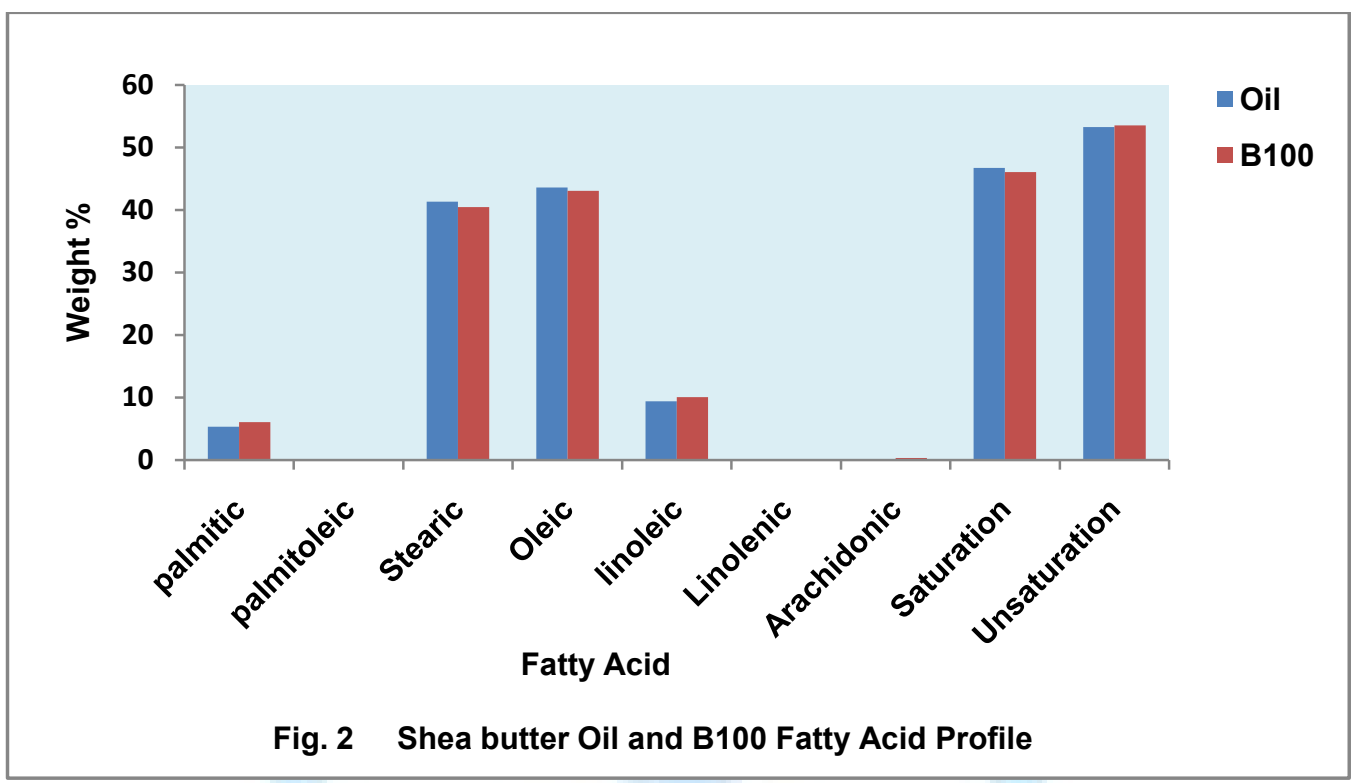

\subsection{Sodium and Potassium}

The oil contained $0.2224 \mathrm{mg} / \mathrm{kg}$ sodium while the B100 contained $0.0009 \mathrm{mg} / \mathrm{kg}$. The sodium content increased after blending due to the residual sodium used as the catalyst in the biodiesel. Only very small amount of potassium was detected and is the least of all the elements investigated. The amount of potassium in B100 is insignificant and tends to decrease with higher amount of biodiesel in the blend because of the diluting effect of diesel fuel used.

\subsection{Calcium}

The oil contains $0.3178 \mathrm{mg} / \mathrm{kg}$ and reduces to $0.2131 \mathrm{mg} / \mathrm{kg}$ for B100, which shows that part of the initial calcium in the oil has been absorbed into the glycerol. The values for B10 and B20 are lower than in the biodiesel due to the diluting effects of the added diesel and probably residual calcium in the washing water.

\subsection{Magnesium}

The oil contained $0.6319 \mathrm{mg} / \mathrm{kg}$ magnesium and reduced by $50 \%$ after transesterification. The amount in the blend reduced by $50 \%$ as the amount of biodiesel is doubled. Fig. 5 shows the result.

\subsection{Sulphur}

The oil contained $1.8316 \mathrm{mg} / \mathrm{kg}$ of sulphur and decreased to $0.0529 \mathrm{mg} / \mathrm{kg}$ after transesterification. The amount in the B10 is $0.0036 \mathrm{mg} / \mathrm{kg}$ and increase to $0.0047 \mathrm{mg} / \mathrm{kg}$ in B20. The sulphur content increases slightly because the diesel also contains some sulphur. Sulphur is desirable in fuel as it contributes to reducing friction, but is very corrosive. The high sulphur content is responsible for its bleaching property and hence the wide spread use as body cream.

\subsection{Phosphorus}

Because it has high melting point, the major parts are not evaporated but remain in the ash hence the amount of phosphorus in the ash is the highest of all the elements investigated. It reduced from $32.0825 \mathrm{to} 3.1962 \mathrm{mg} / \mathrm{kg}$ after transesterification but increased marginally as the amount of biodiesel is doubled. The only source of the increase is the diesel. The result is shown in Fig.7. 


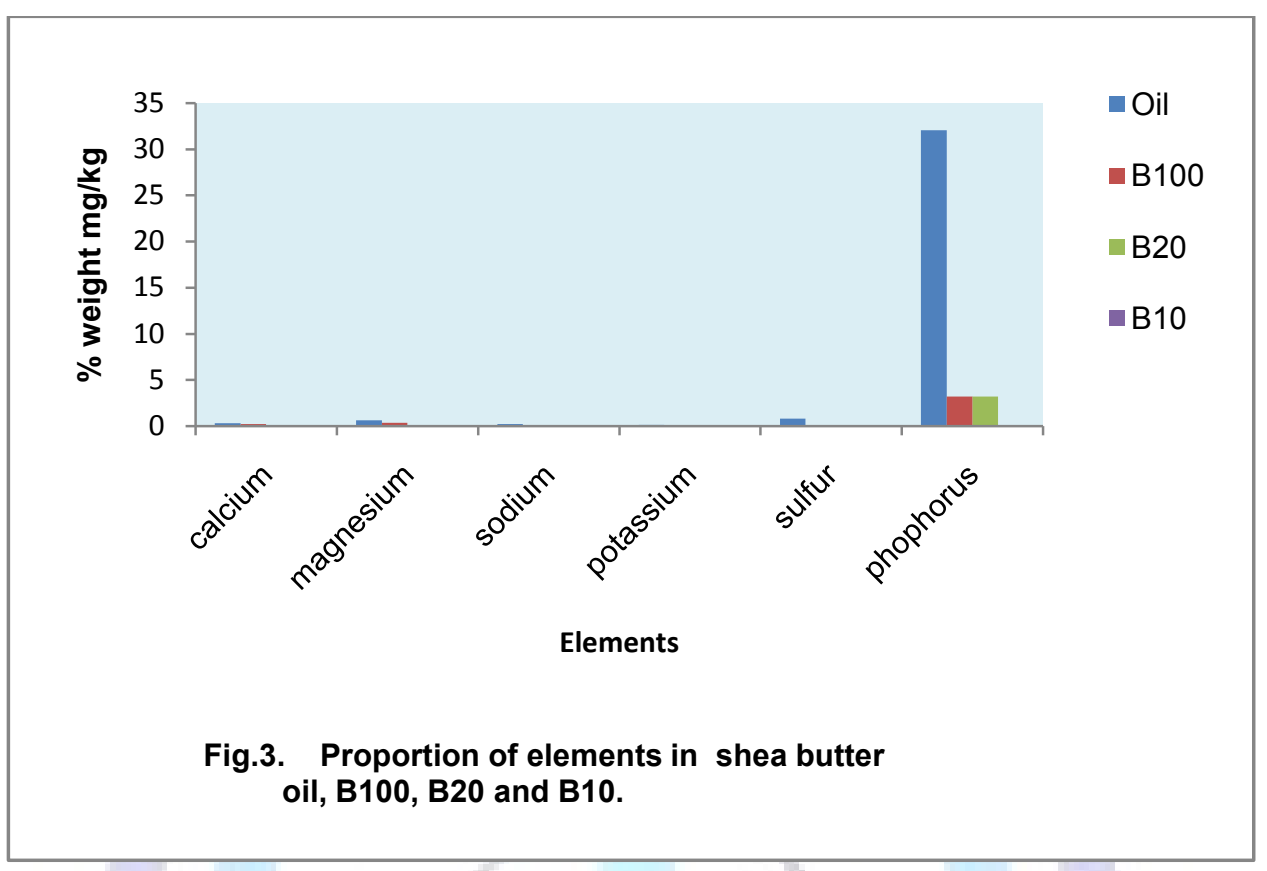

\subsection{CONCLUSIONS}

Shea butter is $53 \%$ unsaturated thus making it a balanced fuel in terms of the saturation/unsaturation ratio. It has a cetane index of 57.6 which is one of the highest for vegetable oils and higher than that of diesel fuel. The iodine value of the biodiesel is 40.40 , which will very much reduce carbon deposit in the engine. The oil has $10 \%$ unsaponifiable matter and is very corrosive hence its use as bleaching and healing cream. All the minerals in the oil were within specifications with the exception of phosphorous. They decreased after transesterification and increased with blending but the increases are not uniform. Most of the properties are within the ASTM limits for biodiesel.

\section{'REFERENCES}

1. Bello. E.I., Agge M., (2011) Performance Evaluation of Egunsi Melon (Citrullus Colocynthis L.) Seeds oil Biodiesel. JETEAS 2(5):74-75.

2. Badifu, G.I.O. (1991) Unsaponifiable Matter in oils from some Species of Cucurbitaceae. J. Food Compos. Anal. $4: 360-365$.

3. Enweremadu CC, Alamu OJ (2010). Development and characterization of biodiesel from Nigerian shea nut butter (Vitellaria paradoxa). Int.Agrophys., 24(1): 29-34.

4. Enweremadu, CC, Rutto, HL \& Oladeji, JT. 2011. Investigation of the relationship between some basic flow properties of shea butter biodiesel and their blends with diesel fuel. International Journal of Physical Sciences. Vol. 6(4), pp. $x x x-x x x$ (in press).

5. Li, CZ; Jiang, IJ; Cheng, SO (2005) Green Energy Resources-Biodiesel. Chemical Industrial Press. Beijing China.

6. Enweremadu, CC; Rutto HL; Peleowo N (2011) Performance Evaluation of a Diesel Engine Fueled with Methyl Ester of shea Butter World Academy of Science, Engineering and Technology 5:109 - 111.

7. Cherng-Yuan Lin and Rong-Ji Lia (2009) Fuel properties of biodiesel produced from the crude fish oil from the soapstock of marine fish . Fuel Processing Technology 90(1):130-136 Lin, CY and H.A. Lin, (2007), Engine performance and emission characteristics of a three-phase emulsion of biodiesel produced by peroxidation, Fuel Processing Technology 88 pp. 35-41.

8. Li, C.Z.; Jiang, L.J.; Cheng, S.Q. (2005) Green Energy Resources-Biodiesel; Chemical Industrial Press: Beijing, China,

9. Reyes, JF and M.A. Sepulveda, PM-10 emissions and power of a diesel engine fueled with crude and refined biodiesel from salmon oil, Fuel 85 (2006), pp. 1714-1719.

10. Lin, CY and H.A. Lin, Diesel engine performance and emission characteristics of biodiesel produced by the peroxidation process, Fuel 85 (2006), pp. 298-305.

11. Willard, WPEngineering Fundamentals of the Internal Combustion Engine, Prentice-Hall Limited, Singapore (1997), pp. 323-325.

12. Parr Instrument Company, Operating Instruction Manual for 1261 Isoperibol Bomb Calorimeter; 1988. 
13. American Oil Chemists' Society, Official Method — peroxide value, cd8; 1980.

14. Cvengros, J. and Z. Cengrosova, Used frying oils and fats and their utilization in the production of methyl esters of high fatty acids, Biomass and Bioenergy 27 (2004), pp. 173-181

15. Knothe, G (2005) Dependence of biodiesel fuel properties on the structure of fatty acid alkyl esters, Fuel Processing Technology 86 (2005), pp. 1059-1070.

16. Zheng, D and M.A. Hanna, Preparation and properties of methyl esters of beef tallow, Bioresource Technology 57 (1996), pp. 137-142.

17. Graboski, MS and R.L. McCormick, Combustion of fat and vegetable oil derived fuels in diesel engine, Progress in Energy and Combustion Science 24 (1998), pp. 125-164.

18. Ma, F., Clements, LD; Hanna MA (1998) Biodiesel fuel from amnimal fat. Ancillary studies on transesterification of beef tallow. Industrial Engineering Chemistry research. 37:3768-3771.

19. Monyem, A and J.H. Van Gerpen, The effect of biodiesel oxidation on engine performance and emission, Biomass and Bioenergy 20 (2001), pp. 317-325.

20. Lin, CY; H.A. Lin and L.B. Hung, Fuel structure and properties of biodiesel produced by the peroxidation process, Fuel 85 (2006), pp. 298-305.

21. Schenk, P.M.; Thomas-Hall, S.R.; Stephens, E.; Marx, U.C.; Mussgnug, J.H.; Posten, C.; Kruse, O.; Hankamer, B. (2008) Second generation biofuels: High-efficiency microalgae for biodiesel production. Bioenergy Res., 1: 20-43. 